\title{
THE IMPACT OF BACKGROUND MUSIC ON THE DURATION OF CONSUMER STAY AT STORES: AN EMPIRICAL STUDY IN MALAYSIA
}

\author{
Keng-Lin Soh \\ Universiti Sains Malaysia \\ K. Jayaraman* \\ Universiti Sains Malaysia \\ Li-Peng Choo \\ Universiti Sains Malaysia \\ Shayan Kiumarsi \\ Universiti Sains Malaysia
}

\begin{abstract}
Consumers spend more time shopping and expect value-added options like background melodious songs, ample car parking, good ambience, prayer halls and rest rooms. The main concern is whether these facilities prolong consumers stay in the store and increase business sales. This research article is about the relationship between the background music tempo and the duration of consumers' stay in the stores. Data from 177 respondents were received and analyzed. The results show that the tempo of music is significantly affecting the emotional state of the consumers; fast tempo music increasing the pleasure and arousal levels. Slow tempo music has consumers stay longer in restaurants and supermarkets. However, the tempo of music does not play a significant role in manipulating the duration consumers spend in a book store and apparel shop.
\end{abstract}

Keywords: Background Music; Arousal; Consumer Behavior; Shopping Experience; StimulusOrganism-Response (S-O-R) Model.

\section{INTRODUCTION}

In the last twenty years, studies concerning the effects of music genre, tempo and rhythm on consumer behavior have increased. Researchers have used different music genres, tempos and rhythms as background music to study consumer behavior. These studies show consumers associate types of music with certain products and making choice of a product over another, or with particular spending patterns and determining the spending on the same type of product. Milliman (1986) found fast tempo background music significantly influence consumer behavior in restaurants. North \& Hargreaves (2008) found music and song lyrics could affect

2 Corresponding author: Assoc. Prof. Dr. K. Jayaraman, Graduate School of Business (GSB), Universiti Sains Malaysia (USM), Penang, Phone: +6010-375 0868, Fax: +604-653 5867 / 2792, E-mail: dr_kjraman@usm.my 
human behavior. In 1993, Areni \& Kim studied consumer behavior in wine purchasing. They compared the effect of classical music with Top Forty background music on consumer behavior and concluded classical music causes consumers choose more expensive wine products. Yalch and Spangenberg (1993) found classical music evokes purchasing higher priced merchandise. However, not all kinds of background music affect consumer behavior. Only when melodies/ music and love songs are played in florist help sales; pop music does not (Guéguen \& Jacob, 2010). In "Musical Fit and Willingness to Pay for Utilitarian Products among University Students", participants were indifferent to purchasing utilitarian products regardless of the type of music or no music at all (Yeoh, 2010). When slow tempo background music is played consumers shop longer and spend more (Milliman, 1982). Patrons at the restaurant are willing to wait for a longer time with slow tempo music (Milliman, 1986). Nicholls (1997) found that the Hispanics who spend more time in the mall consuming food or beverage and would also purchase other products. Therefore by lengthening the time consumers stay in a certain shop would create more business opportunities. The type of background music played in the shop influences consumers' emotions (Ding \& Lin, 2012; Kim, Kim \& Lennon, 2009). Sherman, Mathur, \& Smith (1997) found the relationships between emotional state and duration of consumer stay in the store and spending significant. Increase in spending increases GDP growth. Much research on the effect of background music on a purchasing decision were done and the results are significant (Areni \& Kim, 1993; Milliman, 1982). Yet, there has been little research on duration of consumer stay in shops. Therefore, this study on the effect of background music on duration of consumer stay in shops in Malaysia is timely. This study examines the relationship of background music (slow tempo and fast tempo) with the duration of consumer stay in shops. This research seeks to find answers to the following questions:

i. Does the tempo of music influence the emotions of the consumer?

ii. Does the tempo of music affect the duration of consumer stay in a shop?

iii. Do consumers' emotions influence their duration of stay in a shop?

The results of this study would provide a useful framework on the influence of background music on consumer behavior for future researchers or academicians.

\section{LITERATURE REVIEW}

The studies concerning the effects of musical genre, rhythm, tempo, and modality on consumers' behaviour have become increasingly popular in consumer behaviour literature over the last two decades. Several studies show background music affect human decisionmaking, memory, concentration, task performance and behaviours. But, some studies reported that not all background music affect consumers' behaviour. Milliman (1986) found with slow tempo music in the background could cause patrons in the restaurant stay longer and consume more alcoholic beverages. This is supported by Caldwell and Hibbert (1999). North and Hargreaves (1996) suggested that consumers' 'liking' of the cafeteria increased with their 'liking' of the music being played. When classical, jazz and popular music are played, patrons in restaurants are more willing to spend more on their main meals (Wilson, 2003). Background music has also an effect on shopping behavior. The sales in supermarkets increase when slow tempo background music is played (Milliman, 1982). Consumers would select more expensive wine in a wine store when classical music is played (Areni \& Kim, 1993). 
The money and time spent by shoppers are influenced by their preference of background music (Herrington, 1996). In the open air market, consumers who visit toys and knick-knack stalls stay longer with the presence of background music with the stalls making better sales compared to no music (Guéguen, Jacob, Lourel, \& Guellec, 2007). When love songs and romantic songs are played in the florist, consumers significantly spend more compared to pop music or without background music (Guéguen \& Jacob, 2010). On the contrary, Yeoh (2010) found that musical fit may not influence purchasing intention for utilitarian products. Yalch and Spangenberg (2000) proposed a conceptual model to study the effects of music in a retail setting on real and perceived shopping times (Figure 1).

Music also affects human emotion. When music is added to cancer treatment advertisement, the viewer would feel repentant, skeptical, contempt, coarse and cynical. Besides, the differences between music and no music across pleasure and arousal are also significant for advertisements of Sony, Guess Jeans, and Anti-Fur (Morris \& Boone, 1998, Ridgway et al., 1990). Different music tempo causes different emotional responses. Tempo is seen as an important characteristic in modulating effect (Hevner, 1937). Fast tempo music was found to increase arousal and tension (Husain, Thompson, \& Schellenberg, 2002). Therefore, tempo of music is assumed to influence the happiness, surprise, pleasantness, anger and fear to the listener (van der Zwaag, Westerink, \& van den Broek, 2011). Lundqvist, Carlsson, Hilmersson, and Juslin (2009) found emotion induced in the listener is similar to the emotion expressed in music. Happy music generates more happiness and less sadness when compared with the sad music. This study supports the research for genuine emotional responses to music.

Figure 1: A model integrating store environmental factors, nonverbal responses, and Shopping behaviors

\begin{tabular}{|c|c|c|}
\hline Store Environment & Nonverbal Responses & Shopping Behavior \\
\hline $\begin{array}{l}\text { Music } \\
\text { Color } \\
\text { Scent } \\
\text { Temperature } \\
\text { Layout } \\
\text { Lighting }\end{array}$ & $\begin{array}{l}\text { Pleasure - Displeasure } \\
\text { Arousal - Nonarousal } \\
\text { Dominance - Submissiveness }\end{array}$ & $\begin{array}{l}\text { Time } \\
\text { Exploration } \\
\text { Communication } \\
\text { Satisfaction }\end{array}$ \\
\hline
\end{tabular}

Source: Yalch and Spangenberg (2000).

When rock music is played, more 'rock items' than 'classical items' are recalled and participants recall the 'rock items' earlier than the 'classical items'. When classical music is played, about the same number of 'rock' and 'classical' are recalled, 'classical items' are also recalled earlier (Yeoh \& North, 2010). In addition, background music also affects our concentration and task performance. A study on Taiwanese students' concentration (Chou, 2010) shows that music with a higher intensity is more distracting and has a greater effect 
on task performance and concentration. When background music is played, the attention drainage effect may occur. This is supported by Cassidy and MacDonald (2007) stating task performance is poorer when listening to background music compared with completing task in a silent environment. If the background music is heavy and powerful then wine is perceived also as heavier and more powerful compared with no background music. The mellow and soft background music makes wine taste more mellow and soft; subtle and refined background music makes wine taste zingy and refreshing.

\subsection{A state of mood and emotion}

Interestingly, the general definition of mood is absent from the literature. Lane and Terry (2000) defined mood as a set of feelings, ephemeral in nature, varying in intensity and duration, and usually involving more than one emotion. Mood is a primary mechanism for altering information-processing priorities and for shifting modes of information processing. In other words, mood is to modulate or bias cognition (Davidson et al., 1994). Moods are generally thought to be longer, slower moving and less tied to a specific object if compared to emotion (Rottenberg \& Gross, 2003). Emotions are viewed as coordinated responses that occur when an organism encounters meaningful stimuli that exercise its adaptive capacities. Emotional responses prepare an organism for situational appropriate actions that generally facilitate the survival of species and individuals over the evolution of time (Tooby \& Cosmides, 1990). In other words, emotions are referred as having evolved through the adaptive value in dealing with fundamental life tasks. Each emotion has their unique features, such as signal, physiology and antecedent. Emotion also have their its characteristics such as short duration and automatic appraisal (Ekman, 1992). Emotion state is the transitory conditions of the organism - conditions that can vary substantially, and even rapidly, over the course of a day (Mehrabian, 1996).

Although, mood and emotion are used interchangeably, most of their constructs they present are related but with dissimilar phenomena. The relationship between mood and reaction to situational factors (emotion) is natural. About $60 \%$ of academics and non-academics overlap in their opinion when ranking mood and emotion along eight themes suggesting mood and emotion are different (Beedie, Terry, \& Lane, 2005). Mood is not created by someone because of any event whereas emotions are aroused in people by some specific object or situation. In other words, emotion is a reaction that occurs when an organism encounters meaningful stimuli that calls for adaptive responses. Mood may last for long periods (e.g., a day or a few hours) whereas emotion only last for a second or minutes (Rottenberg, 2005). In this study, emotion is used as an affected feeling after listening to the background music in the stores. Shoppers evaluate shopping trips. The shopper feels when a shop attempts to eliminate human density in the store, there is a feeling of a higher level of gratitude and this brings a higher level of satisfaction (Machleit \& Mantel, 2001). Pleasure has a positive relationship with money spent and in liking the store and arousal also has a positive impact on the money and time spent in the store and the number of items purchased (Sherman et al., 1997). Not everything in the world can be influenced by emotional states. In a study regarding online shopping, Kim (2006) found purchasing intention is not affected by emotional states. But, emotional states still influence the perceived risk and positive attitude towards website attractions. 


\subsection{Duration of stay in store}

Our sense of time is altered by our emotions to such an extent that time seems to drag when we are bored and fly when we have fun. Time can be distorted to appear longer or shorter that it is really is (Droit-Volet \& Meck, 2007). Perception of time can be influenced by the environment stimuli (Kellaris \& Kent, 1992). Besides, there is a study with consumer emotion as a mediating factor and found that arousal has a positive impact on spending and time spent in the store (Sherman et al., 1997). When shopping, we spend different duration of time in different shops. We may spend several hours in supermarket "A" but we only spend fewer minutes in supermarket "B". What leads the consumer to stay longer in a particular store? Researchers studying retail in India found fun and entertainment elements in the store lead consumers spend more time in the store (Ghosh, Tripathi, \& Kumar, 2014). To lengthen the time of patronage, coffee shops should create the feeling of attachment to the community (Waxman, 2006). Besides interior decor, background music may also affect the duration the consumer stay in a restaurant. Milliman (1986) found slow tempo of music makes patrons in the restaurant stay longer when compared to fast tempo. However, tempo of background music did not have a significant impact upon the time spent by consumers in the bar (Down, 2009).

\subsection{Research Framework}

The framework outlined in the study proposed that an environmental stimulus is related to emotional response. Thus, this study uses stimulus-organism-response (SOR) of Mehrabian and Russell (1974) as the supporting theory. According S-O-R, physical or social stimuli in the environment affect an individual's emotional state, which in turn influences a person's behavior such as affiliation, exploration, and physical approach. In S-O-R model, pleasure, arousal and dominance (PAD) is associated with emotional responses which mediates the relationship between the environmental stimuli and an individual's behavior (Figure 2).

Figure 2: Stimulus-Organism-Response (S-O-R) Model

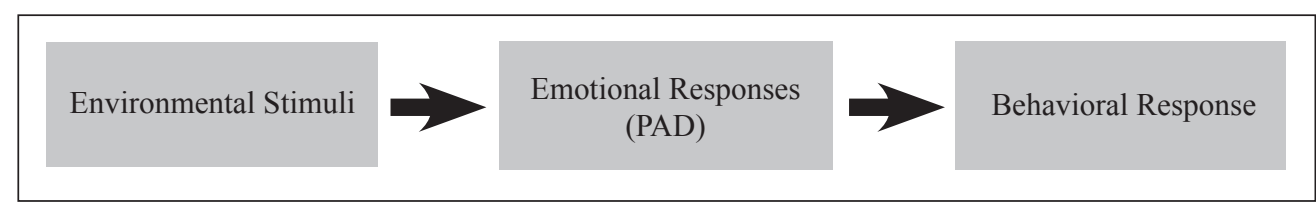

Based on S-O-R paradigm, Mehrabian's theoretical framework outlined that environmental stimuli are related to emotional response and attempts to explain emotional reactions that occur from exposure to stimuli of a particular environment. According to S-O-R, emotional reaction can be classified into three independent states: Pleasure-displeasure, arousal-nonarousal and dominance-passivity. However, dominance factor has proved to be the weakest part of the model in empirical research. Russell and Pratt (1980) proposed to remove the factor of dominance which requires a cognitive rather than an affective judgment on the part of the individual. Thus, in this study, only pleasure and arousal are investigated. Currently, music is not only a pleasurable art form but also serves many important psychological functions. The background music does affect human behavior on decision making. Therefore, many 
researchers have considered music as an element in their study of consumer behavior. The theoretical framework for this study is made up of independent, dependent and mediating variable. The independent variable is the tempo (slow and fast) of background music. The dependent variable is the duration of consumer stay in the store. The background music might affect consumers' emotion (pleasure and arousal) and the emotion affects the duration of consumers' stay in the store. Thus, emotion is added as a mediating variable to investigate the relationship between background music on consumer behavior. The research framework for the study is generated from Figures 1 and 2 and is displayed in Figure 3.

Figure 3: Conceptual Research Framework

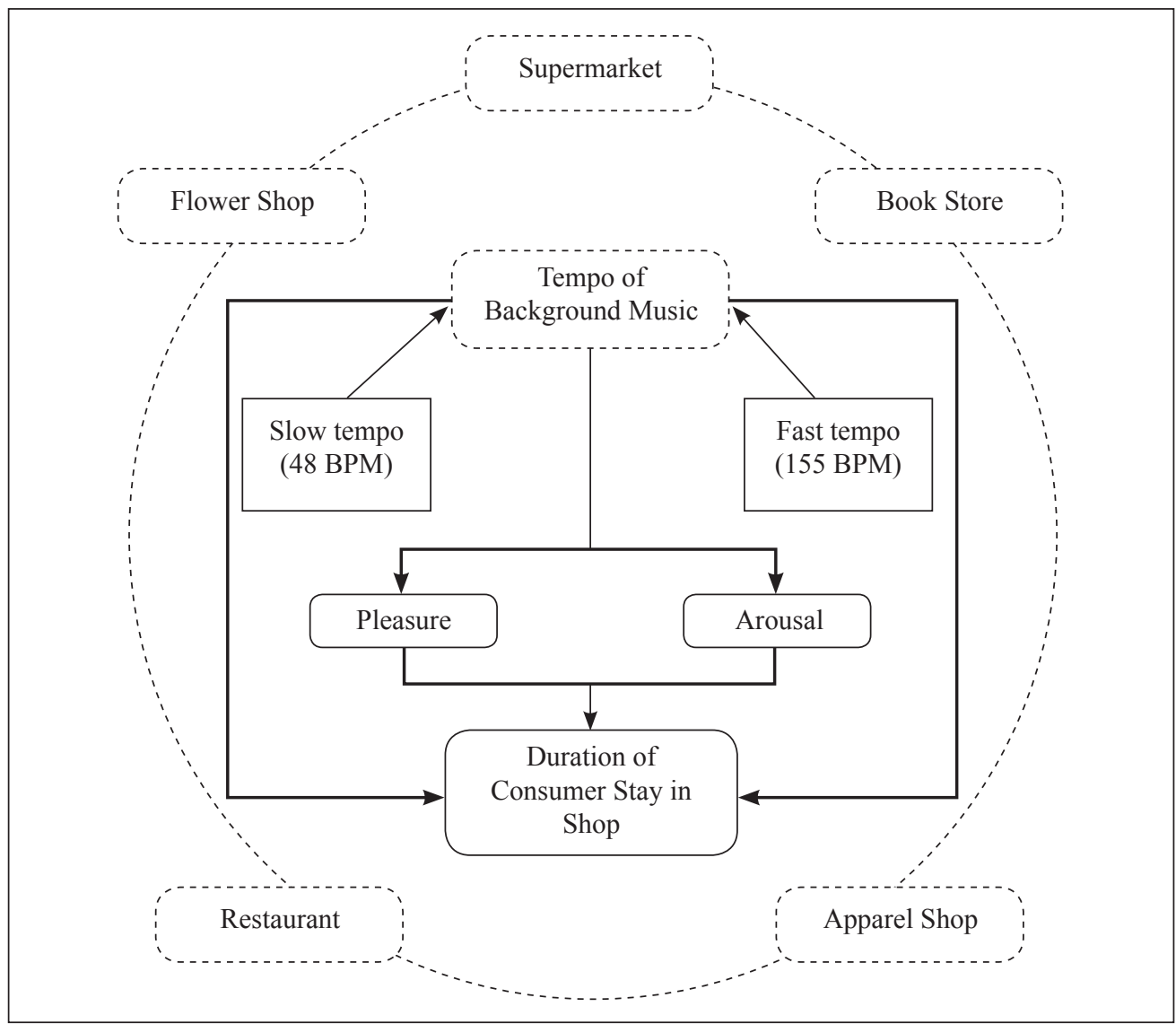

Based on the research framework in Figure 3, three hypotheses are proposed and summarized below:

H1: Background music tempo has a positive influence on the pleasure of the consumers.

H2: Background music tempo has a positive influence on arousal of the consumers. 
H3: Background music tempo has a positive influence on duration of consumers' stay in a shop.

H4: Pleasure and arousal emerging from background music tempo have a positive relationship on the duration of consumers' stay in shops.

\section{RESEARCH METHODOLOGY}

The sample for the study was randomly chosen among the Malaysian population who frequently visit shopping malls and restaurants. According to Sekaran (2003), the rule of thumb for sample size calculation is ten times or more on the number of variables which are included in the research framework. In this study, there are four variables in the framework and therefore about 40 respondents will be sufficient for data analysis. There were two groups of data collected in this study. The first group of respondents listened to slow tempo music and responded whereas the second group of respondents listened to fast tempo music and provided information. This is a cross sectional study where data was gathered only once over a one and a half month period during January and February 2013. The study was confined to willing respondents in the natural environment without any influence. The quantitative research technique was used to analyze the relationship among the variables in the model. A sample was selected based on respondent's education level, with at least secondary school education, so that they can understand the questionnaires and also must have shopping experiences in shops with background music.

\subsection{Measurements of the Instrument}

In the survey questionnaire, music accessible by email was attached in a file for respondents to access. In this study, tempo of the music is measured in "beats per minutes" (BPM). The tempo classification used in the study is based on Milliman (1986). The music that has a BPM of 92 or more is considered fast tempo music and those with 72 BPM or less are considered slow tempo music. In this study, the music of "Angel Eyes" with 155 BPM was chosen as fast tempo music and "Earnest" with 48 BPM was chosen as slow tempo music. Thus, the deviation of these two tempos is 107 BMP to clearly discriminate between the fast and slow tempo music. To measure the emotional state of the respondents, pleasure and arousal dimensions developed by Mehrabian and Russell (1974) were employed. The respondents were asked to rate their feelings on a 7-point semantic differential scale. The pleasure dimension was measured through six items: happy-unhappy, pleased-annoyed, satisfied-unsatisfied, contented-melancholic, hopeful-despairing and relaxed-bored. About six items were used to measure the arousal of respondents; they are stimulated-relaxed, excited-calm, frenzied-sluggish, jittery-dull, wide awake-sleepy and aroused or not aroused. The respondents were also asked to fill in the duration of time they stayed in a restaurant, supermarket, florist, book store and apparel shop in each type of store on an average per trip.

About 500 questionnaires were sent through emails with 250 each for fast and slow tempo music. A total of 117 (23.4\%) respondents filled the questionnaires after listening to the music as per the instructions. Of the 117 respondents, 64 responded to slow tempo music and 53 responded to fast tempo music. The respondents were also requested to state their mood before 
downloading the music which was attached to the questionnaire. Next, the respondents has to play the music. After listening to the music for about 1 to 2 minutes, the respondents' began to answer the questions. The respondents were instructed to place a tick closer to the adjective which best described their feelings. These items were adopted from (Kim, 2006). They were asked to fill in the duration they stayed in different types of stores (restaurant, supermarket, florist, book store and apparel shop) and whether the shop was playing music. The reliability of the scale items was determined by Cronbach's alpha. The Cronbach alpha value which is closer to 1 means the variable has higher reliability. Sekaran (2003) suggested the Cronbach's alpha value is acceptable with a minimum value of 0.5. But Nunnally and Bernstein (1994) recommended a Cronbach's alpha value of 0.7 and above as reliable. This study follows Nunnally and Bernstein (1994).

\section{SIGNIFICANT FINDINGS AND RESULTS}

A total of 117 completed questionnaires were used for data analysis. Out of the 117 respondents, $64(55 \%)$ listened to slow tempo music and $53(45 \%)$ fast tempo music. About 60.7 percent of respondents were females and $39.3 \%$ males. All respondents have minimum secondary school education, and the majority are degree holders. Most of the respondents were between the age group of 27 to 35 and no respondent was younger than 22 years nor above 57 years. Most of the respondents were involved in education, operations/production and engineering (Appendix 1). The factor analysis for pleasure and arousal were conducted separately. The results show Barlett's test of Sphericity is significant for pleasure and arousal and the KMO, a measure of sampling adequacy, is also above the acceptable level of 0.7 . The anti-image correlation matrix results indicated that all the question items have measurement of sampling adequacy (MSA) above the acceptable level of 0.5 . The main factor loadings and Cronbach's alpha for pleasure and arousal are shown in Table 1.

Table 1: Factor loadings and Reliability Analysis

\begin{tabular}{lcc}
\hline Question Item & Factor Loadings & Cronbach's Alpha \\
\hline Pleasure Dimensions & 0.829 & 0.921 \\
Unhappy/Happy & 0.872 & \\
Annoyed/Pleased & 0.885 & \\
Unsatisfied/Satisfied & 0.857 & \\
Melancholic/Contented & 0.848 & 0.834 \\
Despairing/Hopeful & 0.826 & \\
Bored/Relaxed & & \\
& & \\
Arousal Dimensions & 0.536 & \\
Relaxed/Stimulated & 0.696 & \\
Calm/Excited & 0.765 & \\
Sluggish/Frenzied & 0.831 & \\
Dull/Jittery & 0.796 & \\
Sleepy/Wide Awake & 0.819 & \\
Non-aroused /Aroused &
\end{tabular}




\subsection{Results of Discriminant Analysis}

The two-group discriminant analysis was applied to test the effects of two different tempos of the music towards the arousal and pleasure on the duration of stay in 5 different types of shops. The discriminant analysis is a powerful technique for examining differences between two or more groups of objects with respect to several variables simultaneously (Klecka, 1980). The discriminant analysis model fits well to the data as the probability of correct classification is more than 0.7. From the results shown in Table 2, we infer that the difference in tempo of music is positively influenced by the level of pleasure and arousal of the respondents and is significant at $1 \%$ level. Hence, hypotheses $\mathrm{H} 1$ and $\mathrm{H} 2$ are supported. The respondents remarked they are less pleasured and aroused after listening to the slow music tempo. The tempo of music positively influences the duration of stay in restaurant and supermarket at the $5 \%$ significant level. Thus, the hypotheses $\mathrm{H} 3$ and $\mathrm{H} 4$ are partially supported and confined to supermarket and restaurants. These indicate clearly that the respondents prefer to listen to the slow music tempo whenever they stay longer in shops. However, the tempo of music has no influence on the duration of stay in florist, book store and apparel shop.

Table 2: Summary of Discriminant Analysis between Slow $(\mathrm{n} 1=64)$ and Fast $(\mathrm{n} 2=53)$ tempo of music

\begin{tabular}{lccccc}
\hline \multicolumn{5}{c}{ Tests of Equality of Group Means } \\
\hline \multicolumn{1}{c}{ Variable } & $\begin{array}{c}\text { Wilks' } \\
\text { Lambda }\end{array}$ & F & df1 & df2 & Sig. \\
& 0.831 & 23.400 & 1 & 115 & 0.000 \\
\hline Mean Pleasure** & 0.815 & 26.095 & 1 & 115 & 0.000 \\
Mean Arousal** & 0.959 & 4.866 & 1 & 115 & 0.029 \\
Average duration in Restaurant* & 0.954 & 5.534 & 1 & 115 & 0.020 \\
Average duration in Supermarket* & 0.989 & 1.280 & 1 & 115 & 0.260 \\
Average duration in Flower Shop & 0.989 & 1.298 & 1 & 115 & 0.257 \\
Average duration Book in Store & 0.997 & 0.369 & 1 & 115 & 0.545 \\
Average duration in Apparel Shop & & $0.744(74.4 \%)$ & & \\
Probability of Correct Classification & & & & & \\
\hline
\end{tabular}

Notes: $* * \mathrm{P}<0.001, * \mathrm{P}<0.05$

\section{DISCUSSIONS AND IMPLICATIONS}

It is worthwhile to mention that the tempo of music has significant impact on the pleasure and arousal of the consumers. Fast tempo music gives the respondents more pleasure and arousal than slow tempo music. This result is consistent with previous research on emotions citing fast tempo music increases arousal (Husain et al., 2002). This is also supported by the first hypotheses ( $\mathrm{H} 1$ and $\mathrm{H} 2)$ and that is the background music tempo has an influence on pleasure and arousal of the consumers. Since the tempo of music has a significant effect on a person's emotion, listening to fast tempo music would give more pleasure and arousal. For online shopping of hedonic products, arousal and pleasure are very crucial and important. These factors enhance the value perceived by the consumers (Ding \& Lin, 2012). Hence, an online 
marketer for hedonic products should include fast tempo background music in websites. From the output of two-group discriminant analysis, as shown in Table 2, we infer that the tempo of music has a significant effect on certain types of shop. The slow tempo of background music lengthens the duration of patrons in a restaurant, super market and this is supported by Milliman (1986). However, the tempo of music does not have any significant effect on the duration of stay in the florist, book store and apparel shop. In fact, most florists do not play any background music during business hours. Customers in book stores and apparel shops concentrate on the choice of the books and clothes they want to purchase rather than listening to the music.

The study reveals that tempo of music influence the individual's emotion. By listening to music it often regulates the mind to carry out the daily routine. Since music can affect emotions, the understanding and selection of appropriate music in a desired situation is useful. Music not only influences the emotion of the listener, but also affects the duration of consumers' stay in supermarkets and restaurants. These findings are consistent with Milliman (1982 and 1986). The findings would help the marketing manager or shop manager to influence consumer behavior. Care may be taken for the choice of music to match the intended purpose. Undoubtedly during the lean business period, some restaurant and supermarket operators would like to keep the consumers in the shop as long as possible in an attempt to encourage them to purchase more. However, if the objective is to encourage consumers to leave a packed premises, then as soon as they have eaten or bought their merchandise, these operators could refrain from playing the background music to prevent the prolonged occupation of seats or overcrowding in these establishments. For instance, a fast food restaurant would not have sufficient seats during a peak period can play a fast tempo music to quickly clear the consumers. Therefore, the choice of music in a shop must be aligned with the goals of the firms otherwise it would bring about opposite outcomes.

Online business is getting more popular nowadays. We see many shopping websites without background music. The owner of the virtual shops should consider adding the background music to their websites. In order to sell hedonic products, fast tempo music is recommended because it increases the arousal and pleasure of the online shopper which increases the perceived value of the product. Playing background music with correct tempo that matches business goals would help shops achieve their targets. On the other hand, supermarkets should play slow tempo background music during business hours to prolong the duration of the consumers to stay in the mall increasing business opportunities. While background music is normally played out in conventional shops, it is also useful to try out in virtual shops. Online shoppers would feel more aroused and pleasured if they are attached to fast tempo background music. The arousal and pleasure caused by fast tempo music enhances the perceived value would increase shopping intentions.

\section{ACKNOWLEDGMENT}

The authors are most grateful to the editor and reviewers for their valuable suggestions and comments which have really enhanced the quality of the research article considerably. 


\section{REFERENCES}

Areni, C. S., \& Kim, D. (1993). The Influence of Background Music on Shopping Behavior: Classical Versus Top-Forty Music in A Wine Store. Advances in Consumer Research, 20, 336-340.

Beedie, C., Terry, P., \& Lane, A. (2005). Distinctions between emotion and mood. Cognition \& Emotion, 19(6), 847-878.

Caldwell, C., \& Hibbert, S. A. (1999). Play That One Again: the Effect of Music Tempo on Consumer Behaviour in A Restaurant. European Advances in Consumer Research, 4, 58-62.

Cassidy, G., \& MacDonald, R. A. R. (2007). The effect of background music and background noise on the task performance of introverts and extraverts. Psychology of Music, 35(3), 517-537.

Chou, P. T. M. (2010). Attention Drainage Effect: How Background Music Effects Concentration in Taiwanese College Students. Journal of the Scholarship of Teaching and Learning, 10(1), 36-46.

Davidson, R. J., Ekman, P., Frijda, N. H., Goldsmith, H. H., Kagan, J., Lazarus, R., Panksepp, J., Watson, D., \& Clark, L. A. (1994). How are emotions distinguished from moods, temperament, and other related affective constructs? In P. Ekman \& R. J. Davidson (Eds.), The nature of emotion: Fundamental questions (pp. 49-96). New York, NY, US: Oxford University Press.

Ding, C. G., \& Lin, C.-H. (2012). How does background music tempo work for online shopping? Electronic Commerce Research and Applications, 11(3), 299-307.

Down, S. J. (2009). The effect of tempo of background music on duration of stay and spending in a bar. Master Degree, University of Jyväskylä.

Droit-Volet, S., \& Meck, W. H. (2007). How emotions colour our perception of time. Trends in cognitive sciences, 11(12), 504-513.

Ekman, P. (1992). An argument for basic emotions. Cognition \& Emotion, 6(3-4), 169-200.

Ghosh, Tripathi, \& Kumar, (2014). Impact of Shopping Experience on Consumer Loyalty: An Empirical Study of Organized and Unorganized Retailers in India, SOSIOHUMANIKA:Jurnal Pendidikan Sains Sosial dan Kemanusiaan, 7(1), Mei 2014.

Guéguen, N., \& Jacob, C. (2010). Music Congruency and Consumer Behaviour: An ExperimentalField Study. International Bulletin of Business Administration, ISSN: 1451-243X(9), 56-63.

Guéguen, N., Jacob, C., Lourel, M., \& Guellec, H. L. (2007). Effect of Background Music on Consumer's Behavior: A Field Experiment in an Open-Air Market. European Journal of Scientific Research, 16(2), 268-272. 
Herrington, J. D. (1996). Effects of music in service environments: a field study. Journal of Services Marketing, 10(2), 26-41.

Hevner, K. (1937). The Affective Value of Pitch and Tempo in Music. The American Journal of Psychology, 49(4), 621-630.

Husain, G., Thompson, W. F., \& Schellenberg, E. G. (2002). Effects of Musical Tempo and Mode on Arousal, Mood, and Spatial Abilities. Music Perception: An Interdisciplinary Journal, 20(2), 151-171.

Kellaris, J., \& Kent, R. (1992). The influence of music on consumers' temporal perceptions: Does time fly when you're having fun? Journal of Consumer Psychology, 1(4), 365-376.

Kim, J-H. (2006). The Effect of Amount of Information and Music on Consumer Shopping Behaviors in an Online Apparel Retailing Setting. Degree Doctor of Philosophy in the Graduate School, The Ohio State University.

Kim, J-H., Kim, M., \& Lennon, S. J. (2009). Effects of web site atmospherics on consumer responses: music and product presentation. Direct Marketing: An International Journal, Vol. 3(1), 4 - 19.

Klecka, W. R. (1980). Discriminant Analysis. USA: Sage Publications, Inc.

Lane, A. M., \& Terry, P. C. (2000). The Nature of Mood: Development of a Conceptual Model with a Focus on Depression. Journal of Applied Sport Psychology, 12(1), 16-33.

Lundqvist, L.-O., Carlsson, F., Hilmersson, P., \& Juslin, P. N. (2009). Emotional responses to music: experience, expression, and physiology. Psychology of Music, 37(1), 61-90.

Machleit, K. A., \& Mantel, S. P. (2001). Emotional response and shopping satisfaction: Moderating effects of shopper attributions. Journal of Business Research, 54(2), 97106.

Mehrabian, A. (1996). Pleasure-arousal-dominance: A general framework for describing and measuring individual differences in Temperament. Current Psychology, 14(4), 261-292.

Mehrabian, A., \& Russell, J. A. (1974). An approach to environmental psychology. Cambridge, Mass.: The Mit Press.

Milliman, R. E. (1982). Using Background Music to Affect the Behavior of Supermarket Shoppers. Journal of Marketing, 46(3), 86-91.

Milliman, R. E. (1986). The Influence of Background Music on the Behavior of Restaurant Patrons. Journal of Consumer Research, 13(2), 286-289.

Morris, J. D., \& Boone, M. A. (1998). The Effects of Music on Emotional Response, Brand Attitude, and Purchase Intent in an Emotional Advertising Condition. Advances in Consumer Research, 25(1), 518-526. 
Nicholls, J. A. F. (1997). Time and companionship: key factors in Hispanic shopping behavior. Journal of Consumer Marketing, 14(3), 194-205.

North, A. C., \& Hargreaves, D. J. (1996). The Effects of Music on Responses to a Dining Area. Journal of Environmental Psychology, 16(1), 55-64.

North, A. C., \& Hargreaves, D. J. (2008). The social and applied psychology of music. UK: Oxford University Press.

Nunnally, J. C., \& Bernstein, I. H. (1994). Psychometric Theory (3rd ed.). NY: McGraw-Hill, New York.

Ridgway, N. M., Dawson, S. A., \& Bloch, P. H. (1990). Pleasure and arousal in the marketplace: Interpersonal differences in approach-avoidance responses. Marketing Letters, 1(2), $139-147$.

Rottenberg, J. (2005). Mood and Emotion in Major Depression. Current Directions in Psychological Science, 14(3), 167-170.

Rottenberg, J., \& Gross, J. J. (2003). When Emotion Goes Wrong: Realizing the Promise of Affective Science. Clinical Psychology: Science and Practice, 10(2), 227-232.

Russell, J. A., \& Pratt, G. (1980). A description of the affective quality attributed to environments. Journal of Personality and Social Psychology, 38(2), 311-322.

Sekaran, U. (2003). Research Methods for Business: A Skill Building Approach. Singapore: John Willey \& Sons, Inc.

Sherman, E., Mathur, A., \& Smith, R. B. (1997). Store environment and consumer purchase behavior: Mediating role of consumer emotions. Psychology and Marketing, 14(4), 361378.

Tooby, J., \& Cosmides, L. (1990). The past explains the present: Emotional adaptations and the structure of ancestral environments. Ethology \& Sociobiology, 11, 375-424.

van der Zwaag, M. D., Westerink, J. H. D. M., \& van den Broek, E. L. (2011). Emotional and psychophysiological responses to tempo, mode, and percussiveness. Musicae Scientiae, 15(2), 250-269.

Waxman, L. (2006). The Coffee Shop: Social and Physical Factors Influencing Place Attachment. Journal of Interior Design, 31(3), 35-53.

Wilson, S. (2003). The Effect of Music on Perceived Atmosphere and Purchase Intentions in a Restaurant. Psychology of Music, 31(1), 93-112.

Yalch, R. F., \& Spangenberg, E. (1993). Using Store Music for Retail Zoning: A Field Experiment. Advances in Consumer Research, 20(1), 632-636. 
Yalch, R. F., \& Spangenberg, E. (2000). The Effects of Music in a Retail Setting on Real and perceived Shopping Times. Journal of Business Research ,49(2), 139-147.

Yeoh, J. P. S., \& North, A. C. (2010). The effect of musical fit on consumers' memory. Psychology of Music, 38(3), 368-378.

Yeoh, P. S. (2010). Musical Fit and Willingness to Pay for Utilitarian Products Among University Students. Pertanika Journal of Social Sciences and Humanities, 18(1), 1-10.

\section{APPENDIX}

Appendix 1: Profile of the Respondents

\begin{tabular}{lcccccc}
\hline & $\begin{array}{c}\text { Slow Tempo } \\
(\mathbf{n 1}=\mathbf{6 4})\end{array}$ & $\begin{array}{c}\text { Fast Tempo } \\
(\mathbf{n 2}=\mathbf{5 3})\end{array}$ & \multicolumn{2}{c}{$\begin{array}{c}\text { Total } \\
(\mathbf{n}=\mathbf{1 1 7})\end{array}$} \\
\hline \multicolumn{1}{c}{\begin{tabular}{c} 
Socio-Demographic \\
\multicolumn{1}{c}{ Variable }
\end{tabular}} & $\begin{array}{c}\text { No of } \\
\text { Respondents }\end{array}$ & $\mathbf{\%}$ & $\begin{array}{c}\text { No. of } \\
\text { Respondents }\end{array}$ & $\mathbf{\%}$ & $\begin{array}{c}\text { No. of } \\
\text { Respondents }\end{array}$ & $\mathbf{\%}$ \\
\hline Gender & & & & & & \\
Male & 24 & 37.5 & 46 & 39.3 & 22 & 41.5 \\
Female & 40 & 62.5 & 71 & 58.5 & 31 & 58.5 \\
Education & & & & & & \\
Secondary & 1 & 1.6 & 1 & 0.9 & 0 & 0 \\
Diploma & 5 & 7.8 & 14 & 12.0 & 9 & 17.0 \\
Bachelor Degree & 41 & 64.1 & 71 & 60.7 & 30 & 56.6 \\
Master Degree & 16 & 25.0 & 29 & 24.8 & 13 & 24.5 \\
PhD & 1 & 1.6 & 2 & 1.7 & 1 & 1.9 \\
Age & & & & & & \\
22-26 & 9 & 14.1 & 15 & 12.8 & 6 & 11.3 \\
27-31 & 19 & 29.7 & 36 & 30.8 & 17 & 32.1 \\
32-36 & 31 & 48.4 & 55 & 47.0 & 24 & 45.3 \\
>36 & 5 & 7.8 & 11 & 9.4 & 6 & 11.3 \\
Job & & & & & & \\
Operation/ Production & 10 & 15.6 & 17 & 14.5 & 7 & 13.2 \\
Administration & 2 & 3.1 & 5 & 4.3 & 3 & 5.7 \\
Engineering & 10 & 15.6 & 15 & 12.8 & 5 & 9.4 \\
Finance/ Accounting & 4 & 6.3 & 12 & 10.3 & 8 & 15.1 \\
Human Resource & 2 & 3.1 & 3 & 2.6 & 1 & 1.9 \\
Sales/ Marketing & 6 & 9.4 & 10 & 8.5 & 4 & 7.5 \\
Education & 14 & 21.9 & 21 & 17.9 & 7 & 13.2 \\
Information Technology & 4 & 6.3 & 7 & 6.0 & 3 & 5.7 \\
Others & 12 & 18.8 & 27 & 23.1 & 15 & 28.3 \\
\hline & & & & & &
\end{tabular}

